Gut, 1976, 17, 1001-1006

\title{
Effect of intraluminal oxygen on experimental ischaemia of the intestine
}

\author{
K. SHUTE \\ From the Department of Surgery, St. Thomas' Hospital, London
}

SUMMARY The small bowel of 44 rats has been made ischaemic for 120 minutes by occluding the superior mesenteric artery. Gaseous oxygen was introduced into the small bowel lumen of 18 of the rats, and gaseous nitrogen into the bowel lumen of a further eight, 30 minutes after the start of the ischaemia. The mortality rate of thecontrol group of 18 rats was $89 \%$, significantly higher than the $39 \%$ mortality of the oxygen-treated rats $(\mathrm{P}<0.005)$. None of the eight rats treated with intraluminal nitrogen survived. Histological changes caused by ischaemia were much reduced in the intestine of the oxygen treated rats. It is suggested that intraluminal oxygen might be a useful additional form of therapy for the treatment of the partially ischaemic bowel that may be retained after the resection of definitely non-viable ischaemic bowel at initial laparotomy.

Acute massive ischaemia of the small bowel accounts for approximately one in every 1000 admissions to general hospitals (Laufman and Scheinberg, 1942; Ottinger and Austen, 1967). It is usually caused by occlusion of the superior mesenteric artery (SMA) from thrombosis on atheroma or by embolism, but $10 \%$ of cases follow venous thrombosis (Britt and Cheek, 1969) and, in at least $30 \%$ of cases, no major vessel occlusion can be found (Williams et al., 1967; Renton, 1972). These cases of non-occlusive intestinal ischaemia are usually associated with low flow states, particularly cardiac failure (Pierce and Brockenbrough, 1970).

The mortality of massive intestinal ischaemia remains above $80 \%$ (Ottinger and Austen, 1967; Hadded, 1974), and, as stated by Marston (1964) 'occlusion of the main artery to the small bowel leads to death more certainly, and often more quickly than occlusion of a main coronary artery'.

It has been shown experimentally (Shapiro et al., 1958; Milliken et al., 1965) that, after a critical period of SMA occlusion, restoration of the blood supply to the intestine leads to death more quickly than does continuation of the occlusion. This apparently paradoxical behaviour is probably caused by a number of factors, including haemorrhage from the damaged mucosa (Marston, 1963), gross metabolic acidosis (Robertson et al., 1969), and flooding of the systemic circulation with vasoactive agents as a result of an increased permeability of the damaged mucosal cells (Nelson and Noyes, 1952; Lillehei and Received for publication 26 July 1976
Maclean, 1958; Kobold and Thal, 1963; Gurd, 1965; Lefer and Martin, 1970; Manohar and Tyagi, 1973).

It is extremely difficult to diagnose acute intestinal ischaemia in the early stages, and, by the time patients present for surgery, the condition is well advanced (Bergan, 1967; Boley et al., 1973). Thus, if an experiment involving treatment is to be analogous to the human situation, therapy should be instituted only when ischaemia is well established, and be aimed not only at saving bowel, but also at reducing the mortality produced by the revascularisation.

\section{Methods}

Forty-four adult male Wistar rats weighing $300-400 \mathrm{~g}$ and fed on Spratts Rodent Feeding Diet (Lab diet No. 1) were anaesthetised with intramuscular droperidol $(2 \mathrm{mg})$ and fentanyl $(0.05 \mathrm{mg})$. Midline laparotomy was performed and the base of the superior mesenteric artery (SMA) was isolated, preserving the splanchnic nerves, and occluded with a small bulldog clamp (Fig. 1). The animals were divided into two groups.

CONTROL GROUP

In 18 rats the arterial clamp was left in place for 120 minutes and then released.

TEST GROUP A

In another 18 rats $5 \mathrm{ml} 100 \%$ gaseous oxygen in a plastic syringe was introduced through the wall of the small intestine with a 25 gauge needle at four roughly 


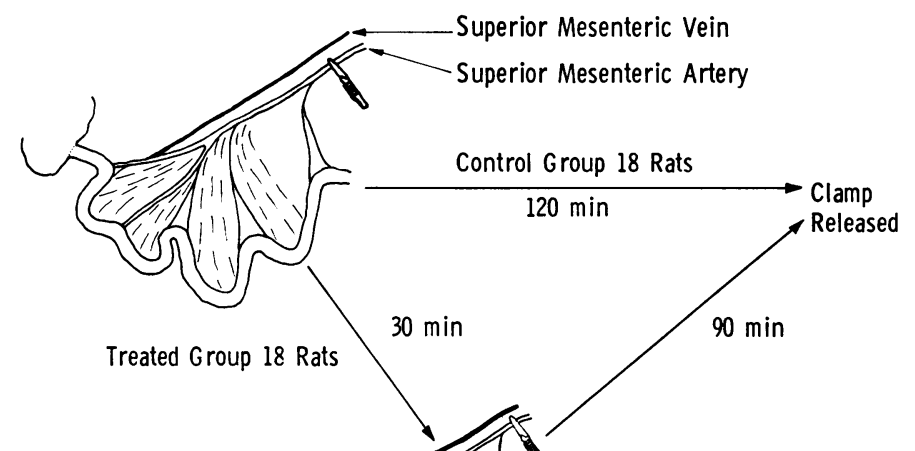

Fig. 1 Experimental superior mesenteric artery occlusion

equidistant points along its length, 30 minutes after starting the aterial occlusion. After an additional 90 minutes, the arterial clamp was released.

The incision was closed and the animals then returned to their cages and allowed to feed at will.

Observations were made of:

1. The macroscopic appearance of the vascular arcades in the mesentery, and the colour, state of distension, and peristaltic activity of the intestine during the ischaemia and after revascularisation.

2. Microscopic changes in the bowel wall after 30 minutes of ischaemia, and five minutes after revascularisation in four additional oxygen-treated and four untreated animals.

3. The rate of respiration during and after SMA occlusion.

4. The mortality in each group 48 hours after SMA occlusion.

5. The length of survival after release of the SMA occlusion in those animals dying before 48 hours.

Necropsy studies were performed on all animals.

TEST GROUP B

The remaining eight rats were subjected to a similar period of SMA occlusion, but $20 \mathrm{ml}$ of gaseous nitrogen was injected into the small bowel lumen after 30 minutes SMA occlusion, to ascertain the effect of distension alone on the mortality.

\section{Results}

\section{MACROSCOPIC CHANGES}

\section{Control group}

After clamping the SMA, its branches rapidly became contracted and remained so during the occlusion. The blood in the superior mesenteric vein (SMV) became increasingly dark during the period of occlusion. The bowel immediately became pale and went into intense spasm. After 30 minutes of SMA occlusion the lower ileum had turned a dusky blue colour which gradually spread to involve most of the bowel after 120 minutes' occlusion.

Release of the arterial clamp resulted in the immediate return of pulsation to the distal mesenteric arteries in every animal, but the intestine did not return to its normal colour, and peristalsis did not recur. The bowel became rapidly distended. In four additional animals the bowel was opened just before revascularisation and revealed that severe haemorrhage occurred from the damaged mucosa after release of the arterial occlusion. This undoubtedly contributed largely to the observed distension of the intestine.

\section{Test group $A$}

After 30 minutes of SMA occlusion, the gross appearances were similar to those seen in the control group. Shortly after injecting the oxygen the bowel wall became pink and remained so until the bowel was replaced in the abdomen after release of the SMA occlusion. Peristalsis started within 10 minutes of injecting the oxygen and continued throughout the experiment.

The dark venous blood in the juxtamural vessels became bright red within 30 seconds and this change spread proximally along the tributaries of the SMV, so that after two to three minutes the whole of the mesenteric venous blood was red.

After releasing the SMA clamp pulsation reap- 
peared in the distal blood vessels. Distension of the intestine was not marked, and much less haemorrhage was seen from the mucosa of the bowel which was opened before revascularisation in four representative animals.

\section{MICROSCOPIC CHANGES}

THIRTY MINUTES AFTER SMA OCCLUSION-BOTH GOUPS (Fig. 2)

The tips of the villi were lost but the bases of the villi and crypts were intact. There was minor haemorrhage into the mucosa. The muscular and serous coats were intact.

\section{FIVE MINUTES AFTER RELEASING THE SMA OCCLUSION}

\section{Control group (Fig. 3)}

There was total loss of the normal architecture of the villi and crypts, many of which had sloughed. The structureless mucosa and submucosa were invaded by leucocytes and gross haemorrhage had occurred into both layers and into the lumen. The muscular and serosal layers were oedematous and minor haemorrhages had occurred into these layers.

Test group $A$ (Fig. 4)

The changes were the same as those seen after only 30 minutes of SMA occlusion.

\section{RESPIRATION (Fig. 5)}

\section{Control group}

The rate of respiration increased gradually during the period of SMA occlusion. After releasing the arterial clamp the respiratory rate rose sharply initially, then more gradually until shortly before the death of the animal. At this time respiration became increasingly shallow, slower and often periodic.

\section{Test group $A$}

A gradual rise in the rate of respiration similar to that seen in the untreated group occurred, until the injection of the oxygen. Thereafter the rate of increase diminished. When the arterial clamp was released there was a further increase in the rate of respiration, but this was less than that of the untreated rats. After one hour the rate of respiration gradually returned to normal, except in those rats which died.

Statistical comparison of the rates of respiration (Student's $t$ test) does not show any significant difference between the two groups until immediately before the release of the SMA clamp, when the mean rates of respiration were 51 per minute in the control

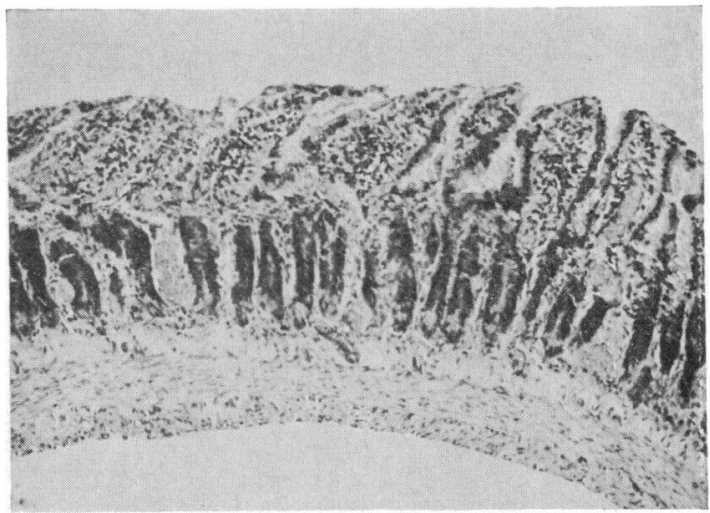

Fig. 2 The microscopic appearance of the intestine after 30 minutes' SMA occlusion. The villi have been lost but the crypts are intact. Minor haemorrhage has occurred into the mucosa.

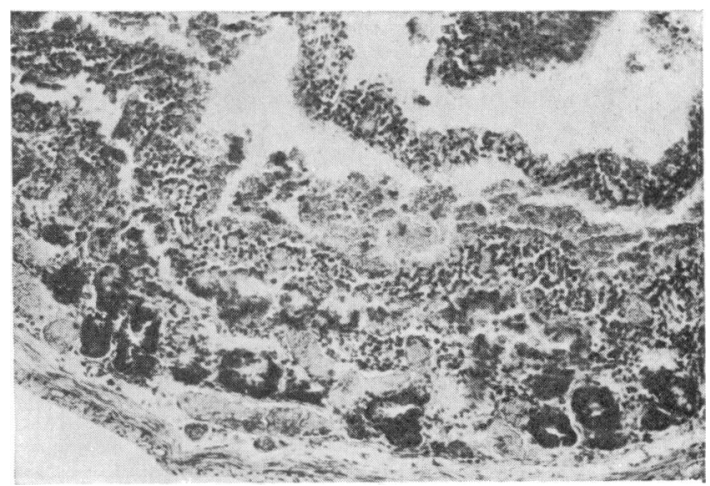

Fig. 3 The microscopic appearance of control rat intestine after release of the SMA clamp at 120 minutes. The crypts have disappeared and the mucosa and submucosal layers are without structure. Gross haemorrhage has occurred into both layers and into the lumen.

group and 44 per minute in the test group $(P=0.02)$. Five minutes and one hour after releasing the arterial clamp the difference between the groups is more significant $(\mathrm{P}=0.002$ and 0.005 respectively).

MORTALITY RATE AT 48 HOURS (Table)

Sixteen of the untreated rats $(89 \%)$ and seven of the oxygen treated rats $(39 \%)$ were dead 48 hours after releasing the SMA occlusion. Statistical comparison of these results ( $\chi^{2}$ test) shows that this is a significant difference-P $=0.005$.

The eight rats treated with the intraluminal nitrogen all died within 48 hours of releasing the SMA occlusion. 


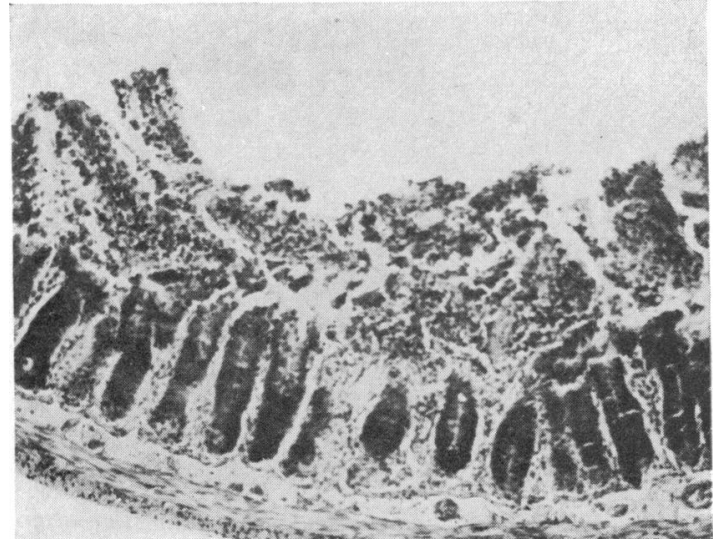

Fig. 4 Oxygen treated intestine after release of the SMA clamp at 120 minutes. The crypts have been preserved and little further change has occurred from that seen in Fig. 2.

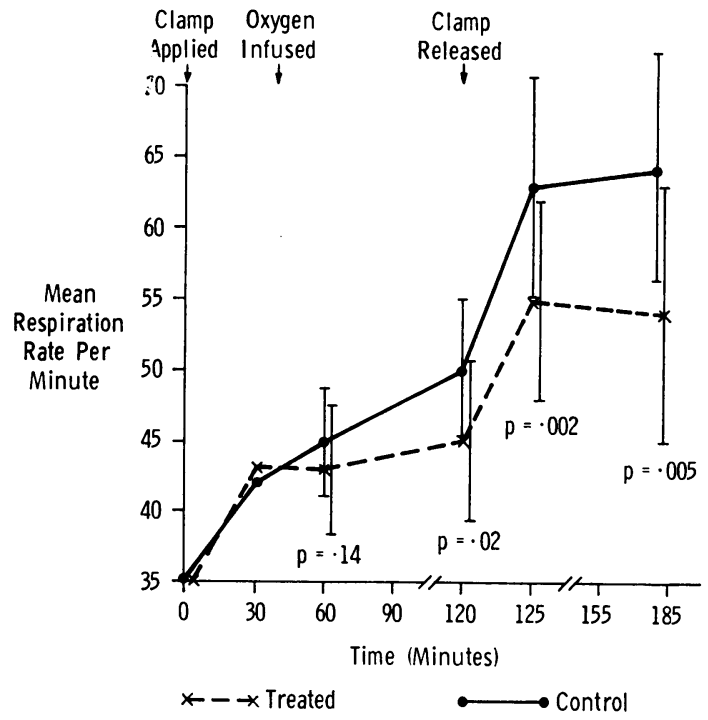

Fig. 5 Respiratory changes during and after occlusion.

DURATION OF SURVIVAL (Fig. 6)

\section{Control group}

Sixteen rats died within 48 hours at times varying from 10 minutes to six hours after releasing the arterial clamp. The mean survival period for all animals was $2 \cdot 7 \pm 1 \cdot 8$ hours.

Test group $A$

Seven rats treated with intraluminal oxygen died from 4.5 to 16 hours after release of the arterial
Table Mortality at 48 hours after occlusion

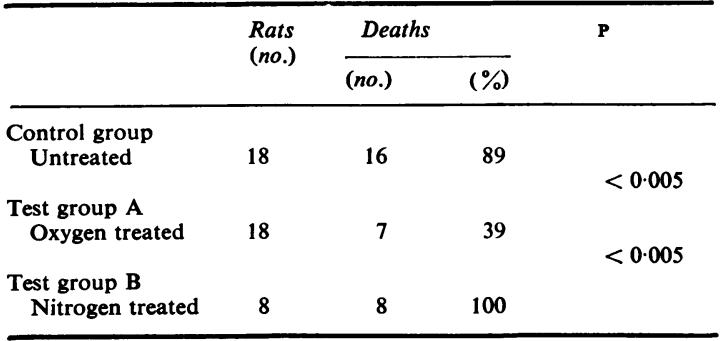

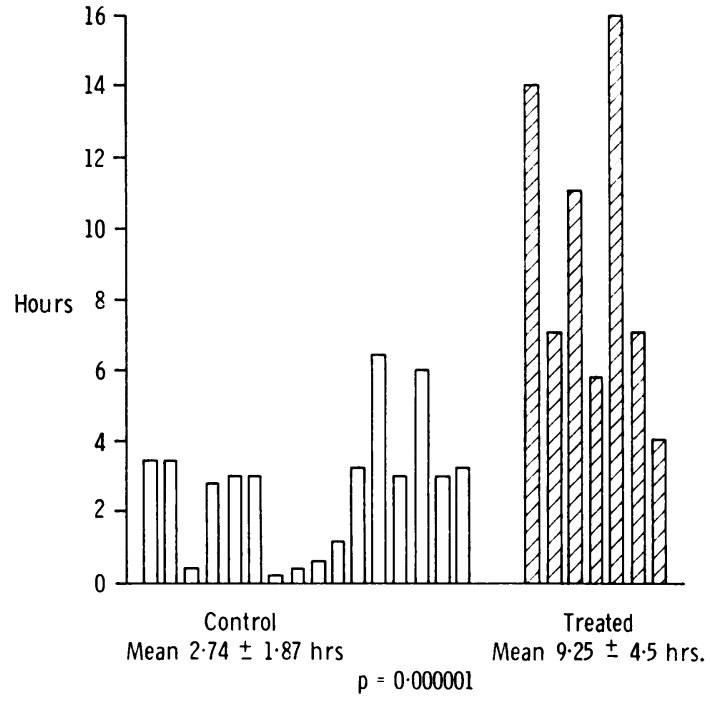

Fig. 6 Duration of survival after release of clamp of animals dying before 48 hours.

clamp, with a mean survival period of $9.25 \pm$ $4 \cdot 5$ hours.

The difference between the control and test groups is highly significant- $\mathrm{P}<0.005$ (Student's $t$ test).

\section{NECROPSY RESULTS}

The findings in all animals from both groups which died before 48 hours were similar. There was serosanguineous fluid present in the peritoneal cavity. Most of the small intestine was plum coloured and the lower ileum was clearly gangrenous. The lumen of the small bowel was filled with altered blood.

In the 13 animals which survived to 48 hours after releasing the SMA occlusion, there were fibrous adhesions between the loops of the bowel and the laparotomy incision. The intestine appeared otherwise normal, but in all survivors there were occasional small abscesses between adjacent loops of bowel. 


\section{Discussion}

Many attempts have been made to decrease the mortality of acute intestinal ischaemia but, although some successes have been claimed in the experimental animal, there has been little improvement in the human situation (Boley et al., 1973; Haddad, 1974). Bounos et al. (1965) have shown that ischaemia of the small intestine causes necrosis of the bowel which begins at the tips of the villi and gradually progresses toward the serosal surface. Chiu et al. (1970) instilled 10\% glucose into ischaemic sacs of canine small intestine and not only prevented further necrosis of the mucosa, but possibly also reversed established damage. These workers showed that, although the cellular integrity could be maintained by anaerobic glycolysis, it led to an accummulation of metabolites and an undesirable lactic acidosis. Little attention had been given to the possibility of giving oxygen directly to the cells until 1973 when Ahren and Haglund perfused isolated loops of ischaemic cat small intestine with oxygenated saline and showed that this reduced the histological changes produced by ischaemia.

During a study of the effect on intestinal blood flow of distension of the intestine produced by injecting air into the lumen, Boley et al. (1969) noticed that, with intraluminal pressures high enough to reduce the total bowel blood flow by $80 \%$, the bowel remained pink. They claimed that this appearance was caused by continued blood flow to the serosa together with a raised oxygen content in the venous blood, but it is equally possible that the oxygen in the injected air was diffusing into the tissues directly supporting metabolism and oxygenating the haemoglobin in the blood vessels.

The experiments described in this paper demonstrate that, when oxygen is introduced into the lumen of ischaemic rat small intestine, it reduces the mortality by $50 \%$. Histological evidence of ischaemia is also diminished. It is likely that the high concentration of oxygen in the lumen sustains the metabolism and integrity of the mucosal cells, thus decreasing both fluid and blood loss into the lumen and the absorption of toxic agents after revascularisation. Studies are continuing into the exact mechanism by which intraluminal oxygen exerts this beneficial effect.

A major difficulty facing surgeons dealing with acute ischaemia of the small intestine is the inability to predict accurately the viability of revascularised intestine (Bussemaker et al., 1972; Skinner et al., 1974). Intestine which is pink with visible pulsation in its walls may become gangrenous after its return to the abdomen. It has been suggested (Jacobson, 1971 ; Boley et al., 1973) that this is due to a pro- longed vasoconstriction after the absorption of toxic vasoactive materials from the lumen. If it were possible to keep the mucosa alive until this vasoconstriction had passed, or, in the case of nonocclusive intestinal ischaemia, until the general circulation were restored to normal limits, the bowel might be saved from irreparable damage. It is suggested that the administration of intraluminal oxygen, to maintain the mucosal integrity in these situations until an adequate blood supply has returned, might improve the survival rate in man.

I am indebted to Professor N. L. Browse for his helpful advice in this study, and to Mrs E. Miles for her secretarial assistance.

\section{References}

Ahren, K., and Haglund, U. (1973). Mucosal lesions in the small intestine of the cat during low flow. Acta Physiologica Scandinavica, 88, 541-550.

Bergan, J. J. (1967). Recognition and treatment of intestinal ischemia. Surgical Clinics of North America, 47, 109-126.

Boley, S. J., Agrawal, G., Warren, A., Veith, F., Levowitz, B., Treiber, W., Dougherty, J., Schwartz, S., and Gliedman, M. (1969). Pathophysiologic effects of bowel distension on intestinal blood flow. American Journal of Surgery, 117, 228-234.

Boley, S. J., Sprayregen, S., Veith, F., and Siegelman, S. (1973). An aggressive roentgenologic and surgical approach to acute mesenteric ischemia. Surgery Annual, 5, 355-378.

Bounos, G., Brown, R., Mulder, D., Hampson, L., and Gurd, F. N. (1965). Abolition of 'tryptic enteritis' in the shocked dog. Archives of Surgery (Chic.), 91, 371-375.

Britt, L., and Cheek, R. (1969). Nonocclusive mesenteric vascular disease: Clinical and experimental observations. Annals of Surgery, 169, 704-711.

Bussemaker, J., and Lindeman, J. (1972). Comparison of methods to determine viability of the small intestine. Annals of Surgery, 176, 97-101.

Chiu, C. J., Scott, H. J., and Gurd, F. N. (1970). Intestinal mucosal lesions in low flow states II. The protective effects of intraluminal glucose as energy substrate. Archives of Surgery, 101, 484-488.

Gurd, F. N. (1965). Metabolic and functional changes in the intestine in shock. American Journal of Surgery, 110, 333-336.

Haddad, H. (1974). Clinical features of ischemic bowel disease. Canadian Journal of Surgery, 17, 435-437.

Jacobson, E. D. (1971). Physiologic aspects of the intestinal circulation. In Vascular Disorders of the Intestine, pp. 19-24. Edited by S. J. Boley, S. S. Schwartz, and L. F. Williams Jr. Appleton-Century-Crofts: New York.

Kobold, E., and Thal, A. (1963). Quantitation and identification of vasoactive substances liberated during various types of experimental and clinical intestinal ischemia. Surgery, Gynecology and Obstetrics, 117, 315-322.

Laufman, H., and Scheinberg, S. (1942). Arterial and venous mesenteric occlusion. Analysis of 44 cases. American Journal of Surgery, 58, 84-92.

Lefer, A., and Martin, J. (1970). Origin of myocardial depressant factor in shock. American Journal of Physio$\log y, 218,1423-1427$.

Lillehei, R. C., and Maclean, L. D. (1958). Intestinal factor 
in irreversible endotoxic shock. Annals of Surgery, 148, 513-525.

Manohar, M., and Tyagi, R. (1973). Experimental intestinal ischemia shock in dogs. American Journal of Physiology, 225, 887-892.

Marston, A. (1963). Causes of death in mesenteric artery occlusion. Annals of Surgery, 158, 952-959.

Marston, A. (1964). Patterns of intestinal ischaemia. Annals of the Roya l College of Surgeons of England, 35, 151-181.

Milliken, J., Nahor, A., and Fine, J. (1965). A study of the factors involved in the development of peripheral vascular collapse following release of the occluded superior mesenteric artery. British Journal of Surgery, 52, 699-704.

Nelson, R. M., and Noyes, H. E. (1952). Permeability of the intestine to bacterial toxins in hemorrhagic shock. Surgical Forum, 3, 474-480.

Ottinger, L., and Austen, W. G. (1967). A study of 136 patients with mesenteric infarction. Surgery, Gynecology and Obstetrics, 124, 251-261.
Pierce, G., and Brockenbrough, E. (1970). The spectrum of mesenteric infarction. American Journal of Surgery, 119, 233-239.

Renton, C. J. (1972). Nonocclusive intestinal infarction. Clinical Gastroenterology, 1, 655-661.

Robertson, G., Lyall, A., and Macrae, J. (1969). Acid-base disturbances in mesenteric occlusion. Surgery, Gynecology and Obstetrics, 128, 15-20.

Shapiro, P. B., Bronsther, B., Frank, E., and Fine, J. (1958). Host resistance to hemorrhagic shock. XI. Role of deficient flow through intestine in development of irreversibility. Proceedings of the Society of Experimental Biology and Medicine, 97, 372-376.

Skinner, D., Zarins, C., and Moossa, A. (1974). Mesenteric vascular disease. American Journal of Surgery, 128, 835-839.

Williams, L. F., Anastasia, L. F., Hasiotis, C. A., Bosniak, M. A., and Byrne, J. J. (1967). Nonocclusive mesenteric infarction. American Journal of Surgery, 114, 376-381. 